\title{
ESTILOS
}

Resenha

Classificação francesa dos transtornos mentais da criança e do adolescente Misès, R. (Org.) (P. V. Silva Júnior, trad.) São Paulo, SP: Instituto Langage, 2018, 168 p.

\section{Classificação e psicopatologia da infância e adolescência: a contribuição francesa chega ao Brasil}

\section{Rossano Cabral Lima ${ }^{1}$}

Há algo novo no reino da nosologia psiquiátrica, pelo menos em terras brasileiras. Finalmente, chega ao país a Classificação Francesa dos Transtornos Mentais da Criança e Adolescente (CFTMEA, em francês), traduzida diretamente da última revisão, de 2012, dirigida por Roger Misès. Até recentemente, os leitores só tinham acesso a esse texto em língua portuguesa de forma indireta, por meio de citações em livros-texto como em Assunção Júnior e Kuczynski (2003), Marcelli e Cohen (2010) e Almeida, Lima, Crenzel e Abranches (2016). Fruto de uma "força-tarefa" de tradutores e colaboradores, liderada pelo psiquiatra e psicanalista brasileiro Palmyr Virginio da Silva Junior, radicado na França desde 1987, o volume é prefaciado pelo psiquiatra e professor da Faculdade de Ciências Médicas da Universidade Estadual de Campinas (FCM-Unicamp) Mário Eduardo da Costa Pereira e tem posfácio escrito pelo psiquiatra e professor da Escola Paulista de Medicina da Universidade Federal de São Paulo (EPM-Unifesp) Miguel Roberto Jorge, além de apresentação do próprio Palmyr Junior.

Os dois sistemas classificatórios mais divulgados globalmente - Manual Diagnóstico e Estatístico de Transtornos Mentais, da Associação Psiquiátrica Americana, atualmente na $5^{\text {a }}$ edição (DSM-5) (American Psychiatric Association [APA], 2014) e a Classificação Internacional de Doenças, da Organização Mundial da Saúde, cuja $11^{\mathrm{a}}$ edição (CID 11) foi lançada on-line em 2018 (World Health Organization [WHO], 2018) -tornaram-se de tal forma hegemônicos (e semelhantes) que ofuscaram a existência de possibilidades distintas de nomear e organizar as psicopatologias, incluindo aquelas da faixa etária infantil e juvenil. Esse é o maior valor da tradução da CFTMEA - apresentar ao mundo psi brasileiro outro modo de descrever as diversas modalidades de sofrimento e distúrbios mentais na criança e no

1. Psiquiatra de crianças e adolescentes. Doutor em Saúde Coletiva pelo Instituto de Medicina Social da Universidade do Estado do Rio de Janeiro (IMS/Uerj). Professor adjunto e vice-diretor do IMS/Uerj, Rio de Janeiro, RJ, Brasil. E-mail: rossanolima1@gmail.com 
adolescente, sem ignorar as classificações "oficiais" da psiquiatria mundial. Na verdade, a CFTMEA dialoga bastante com a CID, sempre buscando correspondências entre as categorias presentes em ambas.

A principal diferença entre a CFTMEA e o par DSM-CID é que a primeira não advoga o ateoricismo, suposta marca das últimas. Pelo contrário, está claro em suas páginas que a psicanálise é a principal chave de leitura dos fenômenos mentais em questão. Assim, a valorização da psicodinâmica e da relação dos sintomas da criança com o meio em que ela habita, em especial com sua família ou quem ocupa essa função, são as marcas que Misès e seu grupo vem imprimindo à classificação desde o seu surgimento, como enfatizam o prefácio e a apresentação da edição brasileira. A psicanálise se faz presente no vocabulário usado na CFTMEA, seja na nomeação das categorias ou subcategorias, como "transtornos neuróticos de predomínio histérico", ou nas referências feitas à "criança pré-edipiana" e aos "autoerotismos" no tópico destinado aos bebês, ou ao "falso-self", "campo transicional", "posição depressiva" e "falhas narcísicas" no grupo das "patologias-limite". Além disso, o texto não se esquiva de fazer referência a grandes autores, e nesse ponto não apenas àqueles mais próximos à psicanálise, como M. Mahler e Bowby, mas também a Kanner ou Piaget, demonstrando respeito à tradição do campo $p s i$ e à transmissão feita na relação entre alunos e mestres, o que parecia ter sido abandonado depois que a medicina baseada em evidências colocou a "opinião de especialistas" nos últimos lugares da hierarquia da produção de conhecimento clínico-científico (Greenhalgh, 2008).

Em linhas gerais, a CFTMEA se organiza em dois eixos. O eixo I é composto de dez "categorias clínicas de base", sendo as cinco primeiras consideradas as principais, ou seja, têm precedência clínica sobre as demais. A recomendação é que o profissional lance mão de apenas uma delas para cada criança. Estão aí incluídas: categoria 1: transtornos invasivos do desenvolvimento (TID), esquizofrenia, transtornos psicóticos da infância e adolescência; 2: transtornos neuróticos; 3: patologias-limites; 4: transtornos reativos; 0: variações da normalidade.

As demais categorias são consideradas “complementares", podendo ser usadas juntamente a uma das anteriores ou ser elevadas a categoria principal, caso não seja possível classificar o quadro da criança ou adolescente nas de 0 a 4 . São elas: categoria 5: deficiências mentais; 6 : transtornos do desenvolvimento e das funções instrumentais; 7: transtornos de condutas e do comportamento; 8: transtornos de expressão somática; 9: manifestações e sintomas do tipo ansioso, fóbico, compulsivo, conversivo.

O eixo II deve ser utilizado para a descrição dos "fatores associados ou anteriores eventualmente etiológicos", incluindo orgânicos pré, peri e pós-natais, doenças crônicas e problemas psicossociais, como doença mental em familiares, carências afetivas e socioeducativas, maus-tratos, negligências, ruptura de laços e outros elementos do contexto sociofamiliar.

A categoria que abre o CFTMEA é a do grupo do autismo, que aparece associado aos TID - como ocorria nos DSM-III e IV e na CID-10; no DSM-5 e na CID-11, renomeado de transtorno do espectro do autismo (TEA), foi alocado no novo grupo dos transtornos do neurodesenvolvimento - e agrupado com as esquizofrenias e transtornos psicóticos (próximo do que ocorria nos DSM-I e II e na CID-9). Incluem-se aí as "desarmonias psicóticas" (ou desarmonias múltiplas e complexas do desenvolvimento), noção muito usada pela pedopsiquiatria francesa desde os anos 1960 e que, segundo Misès e seu grupo, guarda 
semelhanças com os Multiple Complex Developmental Disorders (MCDD), quadro descrito por pesquisadores da Yale University, nos EUA.

A manutenção do autismo no grupo das psicoses seria um anacronismo da classificação francesa? Não necessariamente. $\mathrm{Na}$ verdade, se por um lado as classificações hegemônicas vêm afastando o autismo das psicoses infantis, a ponto de estas terem quase desaparecido na psiquiatria contemporânea, por outro lado, as possíveis (des)continuidades entre esses quadros, no percurso do desenvolvimento infantil, estão longe de terem sido definidas ou excluídas. Só para citar algumas aberturas presentes nos sistemas CID e DSM, a CID-10 aponta que episódios psicóticos podem ocorrer no início da vida adulta de pessoas com síndrome de asperger (OMS [Organização Mundial da Saúde], 1993), enquanto o DSM-5 inclui a possibilidade de surgimento, especialmente na adolescência de pessoas no espectro autista, de sintomas catatônicos como a flexibilidade cérea, tradicionalmente associada à catatonia da psicose esquizofrênica (APA, 2014). Nesse sentido, o comentário da CFTMEA de que algumas formas de esquizofrenia "podem também constituir um modo de evolução de um TID precoce" (p. 48) não está tão dissonante assim do que afirmam a OMS ou a APA.

Dito isso, é preciso assinalar que os diagnósticos diferenciais dentro desse grupo na CFTMEA são no mínimo confusos - e o próprio texto admite isso, quando comenta, a respeito das "desarmonias psicóticas", que "os critérios de inclusão e exclusão suscitam problemas" (p. 46) e que a psicose simbiótica de Mahler pode ser em parte incluída aí e em parte nos TID de tipo autístico; além disso, crianças atípicas ou esquizoides poderiam fazer parte das desarmonias, mas também das patologias da personalidade ou dos transtornos neuróticos. Essa confusão nos leva a admitir que, até certo ponto, fazia sentido a intenção do grupo que elaborou o DSM-III de construir regras mínimas e um vocabulário básico que colocassem alguma ordem na balbúrdia nosológica dos anos 1960 e 1970. O problema foi que aquilo que deveria ser mínimo e básico acabou eliminando outros modos de se descrever os problemas mentais nas crianças, tornando-se a novilíngua da psiquiatria (Lima, 2015).

Essa questão também aparece em relação ao diagnóstico de depressão. Se concordamos que as classificações oficiais unificaram artificialmente distintas experiências depressivas, melancólicas e distímicas em torno de uma "doença" chamada major depression, empobrecendo a clínica, na CFTMEA as síndromes depressivas estão dispersas, "em função da organização estrutural" (p. 39), nos transtornos do humor da infância ou adolescência (categoria 1), nas depressões neuróticas (categoria 2), nas depressões ligadas a uma patologialimite (categoria 3), nas depressões reativas (categoria 4) e nos momentos depressivos na normalidade (categoria 0), além das depressões do bebê. Quanto menor o nível de especialização dos profissionais - tomemos aqueles da estratégia de saúde da família, por exemplo -, mais difícil será distinguir, tratar ou encaminhar corretamente cada uma dessas variações.

Há pelo menos um ponto no qual a manutenção de um vocabulário da tradição psiquiátrica se revela anacrônica - a categoria "demências", no grupo das deficiências mentais, aplicada a crianças com "redução das capacidades mentais com tendência a evolução em direção a uma limitação maior" (p. 75), relacionada diretamente a fatores orgânicos conhecidos. Essa noção tem lugar importante na história da psiquiatria, tendo sido consagrada na demência precoce de Kraepelin, mas hoje há poucas justificativas para sua utilização para além das demências senis ou pré-senis (Alzheimer, vascular, Pick, Parkinson etc.), especialmente em uma classificação de crianças e adolescentes. 
Há algumas contribuições e inovações da CFTMEA que se mostram claramente vantajosas em relação aos demais sistemas classificatórios. Uma delas é a inclusão do eixo específico para os bebês, dando relevância às peculiaridades das formas de adoecimento psíquico na faixa de zero aos três anos, incluindo as situações consideradas "de risco" para transtornos graves do desenvolvimento, e realçando as relações do bebê com o meio e os laços com os adultos que dele cuidam. Outra particularidade é a presença da categoria 0 - variações da normalidade -, que deixa explícito que há diversas situações que chegam aos serviços ou consultórios e não correspondem necessariamente a patologias mentais, que nem toda aflição ou problema se traduz em uma categoria psiquiátrica e que as fronteiras entre normalidade e patologia não estão fixamente estabelecidas, principalmente quando se trata de seres em modificação permanente de sua constituição física e psíquica.

Também é interessante perceber que o transtorno do déficit de atenção com hiperatividade (TDAH) - carro-chefe da psiquiatria infantil contemporânea, que sempre traz o risco de medicalização e farmacologização de problemas escolares - não está listado dentre as categorias principais, mas sim entre as complementares. Isso vai ao encontro de nossa proposta de considerar o TDAH, sempre que possível, um "diagnóstico de exclusão", a ser utilizado quando outras hipóteses, não apenas médicas, mas também relacionais e pedagógicas, forem investigadas e descartadas (Almeida et al., 2016). Esse quadro, na CFTMEA, tem sua forma atencional pura descrita separadamente (6.13 - Transtornos da atenção sem hipercinesia) da forma hiperativo-desatentiva (7.00 - Hipercinesia com transtornos de atenção). Essa concepção é próxima daquela do psicólogo cognitivista norteamericano Russerl Barkley, que defende que as disfunções na base das duas apresentações predominantemente desatenta e predominantemente hiperativa - são distintas (Barkley, 1997).

Por fim, e um pouco menos importante, uma bem-vinda nova edição brasileira deveria realizar uma revisão geral no texto, pois são relativamente frequentes deslizes na digitação e problemas afins. Os mais importantes (mas há diversos outros): "disarmonia" em vez de desarmonia (p. 44, 61, 62); esquizofrenia e esquizoafetivo grafados com "s" ("esquizofrenia") (p. 50, 53) ou com "f" ("esquifofrênico") (p. 51), e "agorofobia" no lugar de agorafobia (p.105), todos esses nas correspondências com a CID-10, espalhadas pelo texto (mas não na tabela ao final). Além disso, na página 123 (14 - Doenças de origem genética ou congênita) o termo "infecção" tomou o lugar de "afecção". Outro problema é que os textos introdutórios trazem informações discrepantes sobre a data da primeira edição da CFTMEA na França. No prefácio, fala-se em 1983 (p. 13); na apresentação, em 1987 (p. 25) e 1990 (p.28). Seria bom, em nova edição ou reimpressões, unificar essa informação.

Como em toda a classificação, há pontos de inconsistência e mesmo de contradição na CFTMEA, alguns deles apontados acima; contudo, nenhum deles ofusca a relevância clínica e acadêmica da publicação da tradução brasileira, sendo apenas necessário - como apontado no posfácio - levar em conta as diferenças socioculturais entre o contexto francês, onde foi elaborado, e o brasileiro (cuidado que também deveria ser tomado em relação ao DSM). É mais que justificado haver um esforço para tornar a CFTMEA acessível a estudantes universitários e residentes do campo psi, pesquisadores e profissionais dos serviços públicos de saúde mental e da prática privada em todo o país. 


\section{Referências}

Almeida, R. S., Lima, R. C., Crenzel, G., \& Abranches, C. D. (2016). Psiquiatria da criança e do adolescente (Série Soperj). Rio de Janeiro, RJ: Gen.

American Psychiatric Association (2014). Manual diagnóstico e estatístico de transtornos mentais: DSM-5. Porto Alegre, RS: Artmed.

Assunção Junior., F. B., \& Kuczynski, E. (2003). Tratado de psiquiatria da infância e adolescência. São Paulo, SP: Atheneu.

Barkley, R. (1997). ADHD and the nature of self control. New York: The Guilford Press.

Greenhalgh, T. (2008). Como ler artigos cientificos. Porto Alegre, RS: Artmed.

Lima, R. C. O DSM entre a novilíngua e a lingua tertii imperii. In R. Zorzanelli, B. Bezerra Junior, \& J. F. Costa (Orgs.). (2015). A criação de diagnósticos na psiquiatria contemporânea (pp. 253-270). Rio de Janeiro, RJ: Garamond.

Marcelli, D., \& Cohen, D. (2010). Infância e psicopatologia (8a ed.). Porto Alegre, RS: Artmed

Organização Mundial da Saúde. (1993). Classificação de transtornos mentais e de comportamento da CID-10: descrições clínicas e diretrizes diagnósticas. Porto Alegre, RS: Artmed.

World Health Organization. (2019). ICD 11: International Classification of Diseases 11th revision. Recuperado de https://icd.who.int/

Recebido em janeiro/2019 - Aceito em março/2019. 